\title{
Abordagem sobre ensaios clínicos para Covid-19 autorizados no Brasil pela Agencia Nacional de Vigilância Sanitária até 30 de junho de 2020.
}

\author{
Approach to clinical trials authorized in Brazil by the \\ National Health Surveillance Agency until June 30, 2020.
}

\author{
Anselmo Gomes de OLIVEIRA; \\ Dâmaris SILVEIRA \\ Editores-chefe
}

Com o surgimento da pandemia do coronavirus, houve uma dedicação intensa e relevante da comunidade científica à procura de novos medicamentos para tratamentos da Covid-19, devido à inexistência de vacinas e à necessidade emergencial de se evitar os óbitos crescentes em decorrência dos efeitos degenerativos no trato respiratório, provocados pela doença no organismo humano, principalmente nos pacientes do grupo de risco.

O tema foi abordado resumidamente no editorial anterior de Infarma - Ciências Farmacêuticas "Tratamento da Covid-19 com medicamentos experimentais em testes clínicos: desafios e perspectivas"(1). Ficou evidente uma variedade de protocolos clínicos aplicados na forma de testes clínicos ou de uso off label de muitos fármacos e medicamentos pelo mundo, tentando explicitar ainda, que embora tenham segurança demonstrada para outras doenças, estudos complementares são necessários para poderem ser utilizados para a ampliação da aplicação para doenças diferentes daquela já aprovada pelas Agências regulatórias. Parece evidente que, na ausência de tratamentos, de forma emergencial e transitória as Agências Regulatórias assim têm procedido tanto para autorizar $(2,3)$ como desautorizar (4).

Assim, nesse pouco tempo, embora a situação não fosse totalmente favorável, muita coisa mudou, no mundo e no Brasil. Os cientistas brasileiros tem se empenhado profundamente procurando alternativas no campo do medicamento, pelo menos para minimizar as perdas naturais que ocorrem numa pandemia intensa que assola a humanidade, particularmente nosso país. É inegável o caráter emergencial pela falta de alternativas para o tratamento principalmente de casos graves e que as pesquisas clinicas ocupam um lugar de destaque na ciência brasileira com o objetivo de confirmar uma relação Efeito terapêutico/Efeito colateral vantajosa.

Na página da Anvisa, foi publicada uma lista, descrevendo os ensaios clínicos para COVID-19 autorizados no Brasil (http://portal.anvisa.gov.br/ documents/33836/2492465/Ensaios +cl\%C3\%AD nicos +-+ covid/9cda8d5c-5abd-4d65-8191-28ee79 $38 \mathrm{e} 90 \mathrm{a})$, mostrando as características principais dos estudos, o protocolo usado nos ensaios clínicos, a empresa patrocinadora, o fármaco ou medicamento estudado, a fase em que se encontra o estudo, o título do estudo em andamento, o registro na base de dados internacional ou no Brasil o qual permite o acesso a informações mais detalhas dos estudos, a previsão de término do estudo e os países participantes juntamente com o Brasil, quando couber (5).

O documento mostra dezoito ensaios autorizados, sendo que um deles foi cancelado a pedido da empresa patrocinadora e outros dezessete deles estão ativos. Dos ensaios clínicos ativos, treze são patrocinados por empresas farmacêuticas, três por empresas de pesquisa clinica e um, por hospital. Dos relatos, onze estudos estão na fase III da execução, um nas fases II e III, três na fase II, um na fase $\mathrm{Ib}$, e outro na fase inicial de prova de conceito. 
Dos dezoito estudos, 17 referem-se a fármacos ou medicamentos aplicáveis no tratamento da COVID-19 e apenas um se refere ao estudo da segurança, eficácia e imunogenicidade de vacina, a "ChAdOx1 nCoV-19 Vaccine" (https://chadox1-ncov-19.com/chadox1-full-form/), desenvolvida pelo grupo de cientistas colaboradores da Universidade de Oxford e que se encontra em fase III de execução, inclusive no Brasil, e não tem previsão de encerramento dos testes (5).

Seguindo a tendência de outros periódicos científicos e considerando a emergência de resposta à pandemia, foi criada em Infarma - Ciências Farmacêuticas uma seção de exposição rápida de artigos, por meio da iniciativa "Covid-19 Fast track" (http://revistas.cff.org.br/?Journal=infarma). Os trabalhos recebidos sobre o assunto, depois de uma análise prévia dos editores, serão colocados on line, antes da revisão pelos pares para a decisão final de aceite. Dessa forma convidamos a comunidade científica atuante em todos os assuntos relacionados, a enviar seus manuscritos. Nesse número, pode ser acessado o primeiro artigo sobre o tema, publicado anteriormente na seção Covid-19 Fast track.

\section{REFERÊNCIAS}

1. Oliveira AG, Silveira D. Tratamento do Covid-19 com medicamentos experimentais em testes clínicos: desafios e perspectivas. Infarma - Ciências Farmacêuticas. 2020;32(1):3-5. DOI: 0.14450/2318-9312.v32.e1.a2020. pp3-5

2. FDA. DHHS Letter Head. Request for Emergency Use Authorization For Use of Chloroquine Phosphate or Hydroxychloroquine Sulfate Supplied From the Strategic National Stockpile for Treatment of 2019 Coronavirus Disease (2020). https://www.fda.gov/ media/136534/download
Ainda, O Conselho Federal de Farmácia (CFF) mantém uma seção com informações e orientações gerais sobre Covid-19 link http://covid19.cff.org. br/materiais-de-apoio/.

Aproveitamos para anunciar que o quadro de Editores Associados de Infarma - Ciências Farmacêuticas foi renovado, com pesquisadores de todas as regiões do Brasil (http://www.revistas. cff.org.br/?journal=infarma\&page=about\&op= editorialTeam).

Dessa forma, damos boas vindas aos novos Editores Associados e agradecemos aos Editores Associados que terminam sua jornada em Infarma - Ciências Farmacêuticas: Dra Lilian Grace da Silva Solon, Dra Hellen Karine Stulzer Koerich, Dr Maurício Homem de Mello, Dr Emilio Vasconcelos Leitão Cunha. Também agradecemos à Dra Tania Mari Belle Bresolin, que continua no quadro de Editores Associados.

Desejamos, a todos os leitores, ótima saúde neste momento complicado de nossas vidas e esperamos que encontrem, neste número de nosso periódico, informações uteis e interessantes para o seu cotidiano.
3. BRASIL. Uso da Cloroquina como terapia adjuvante no tratamento de formas graves do COVID-19, 5/2020-DAF/SCTIE/MS (2020).

4. FDA. Revocation of Emergency Use Authorization for Emergency Use of Chloroquine Phosphate and Hydroxychloroquine Sulfate (2020). https://www.fda. gov/media/138945/download

5. ANVISA. Lista dos Ensaios Clínicos para COVID-19 autorizados pela Anvisa (2020). http://portal.anvisa.gov.br/ documents/33836/2492465/Ensaios+cl\%C3\%ADnicos+ -+covid/9cda8d5c-5abd-4d65-8191-28ee7938e90a 